\title{
Time of occurrence, duration, and ventricular rate of paroxysmal atrial fibrillation: the effect of digoxin
}

\author{
John M Rawles, Malcolm J Metcalfe, Kevin Jennings
}

\begin{abstract}
One hundred and thirty nine episodes of atrial fibrillation were identified from Holter recordings in 72 patients with paroxysmal atrial fibrillation. Paroxysms occurred more often by day than by night, suggesting that attacks are more closely associated with sympathetic than with vagal activity. In 41 patients who were not taking digoxin there were 79 episodes, and in 31 patients who were taking digoxin there were 60 episodes. Significantly more of the episodes that lasted for 30 minutes or more occurred in patients taking digoxin (13/17); the relative risk of a prolonged paroxysm associated with taking digoxin was $4 \cdot 3$ (95\% confidence intervals 1.6-11.9). The mean (SD) ventricular rate at the onset of the paroxysms was not significantly different in those taking digoxin (140 (25) beats/ $\mathrm{min}$ ) and in those who were not (134 (22) beats/min).

In paroxysmal atrial fibrillation, pretreatment with digoxin does not seem to reduce the frequency of paroxysms, or the ventricular rate when paroxysms occur, but it is associated with longer attacks.
\end{abstract}

In paroxysmal atrial fibrillation some patients may experience distressing symptoms at the onset of a paroxysm, symptoms that are related to the tachycardia usually present when atrial fibrillation starts. Digoxin is generally effective in established atrial fibrillation in reducing the ventricular rate of patients at rest. It achieves this effect indirectly by slowing conduction through the atrioventricular node by increasing vagal tone. Digoxin is also sometimes used in paroxysmal atrial fibrillation in the hope that it will reduce the ventricular rate when paroxysms start. ${ }^{12}$ However, in some patients with paroxysmal atrial fibrillation, paroxysms are more likely to occur at times of increased vagal activity, such as during sleep, ${ }^{3}$ so digoxin, with its vagotonic effect, may increase the frequency of attacks. ${ }^{4}$ Moreover, by its action in reducing the atrial refractory period digoxin may make reversion to sinus rhythm less likely. Whether pre-treatment with digoxin is effective in reducing the ventricular rate in paroxysmal atrial fibrillation, or whether digoxin causes attacks to be more prolonged is not known.

Since autonomic tone affects the likelihood of the occurrence and perpetuation of atrial fibrillation, variation of the rate of occurrence of attacks would be expected in parallel with the known diurnal variation of 'autonomic activity. ${ }^{5}$ In this study we noted the times of day that episodes of atrial fibrillation occurred. We also compared the ventricular rates at the onset of paroxysms, and noted the number of prolonged paroxysms, in patients with and without digoxin therapy.

\section{Patients and methods}

We selected Holter recordings showing paroxysmal atrial fibrillation in 72 consecutive patients who were being investigated for clinical reasons. All patients were in sinus rhythm at the start and end of the recordings, which lasted for 48 hours. For the purposes of this study paroxysmal atrial fibrillation was defined as the occurrence of at least five beats of supraventricular origin, with a totally irregular ventricular response, with no visible $P$ or flutter waves, the arrhythmia lasting less than 24 hours. Seventy two patients ( 32 men and 40 women; mean age 72 (range 34-93) had arrhythmias which fulfilled these criteria. Associated diagnoses were as follows: none 45 , ischaemic heart disease 12 , sinoatrial disease 11 , valvar heart disease two, hypertension two. Thirty one patients were taking digoxin, 11 were taking a $\beta$ adrenergic blocker (five with digoxin), and nine were taking a calcium channel blocker (three with digoxin). We calculated the serum concentration of digoxin from the serum creatinine concentration and the body weight, using a nomogram based on the pharmacokinetics of digoxin. ${ }^{6}$ The calculated serum digoxin concentration was $0 \mu \mathrm{g} / 1$ in 41 , up to $1 \mu \mathrm{g} / 1$ in 11 , and over $1 \mu \mathrm{g} / 1$ in 20 patients.

The time of onset of each paroxysm was noted together with the ventricular rate, calculated from the first $5-10$ beats of each paroxysm. In the case of prolonged bouts of atrial fibrillation lasting 30 minutes or more, the duration of the attack and the ventricular rate immediately before it ended were noted.

\section{Results}

TIME OF DAY OF PAROXYSMS (fig 1)

There were 139 paroxysms recorded in 72 patients, an average of 1.9 episodes during a two day recording (range one to seven). Of the total, $26(19 \%)$ paroxysms occurred between the hours of 2200 and $0600,56(40 \%)$ between 0600 and 1400 , and $57(41 \%)$ between 1400 and 
Figure 1 Numbers of paroxysms of atrial fibrillation throughout the day and night.

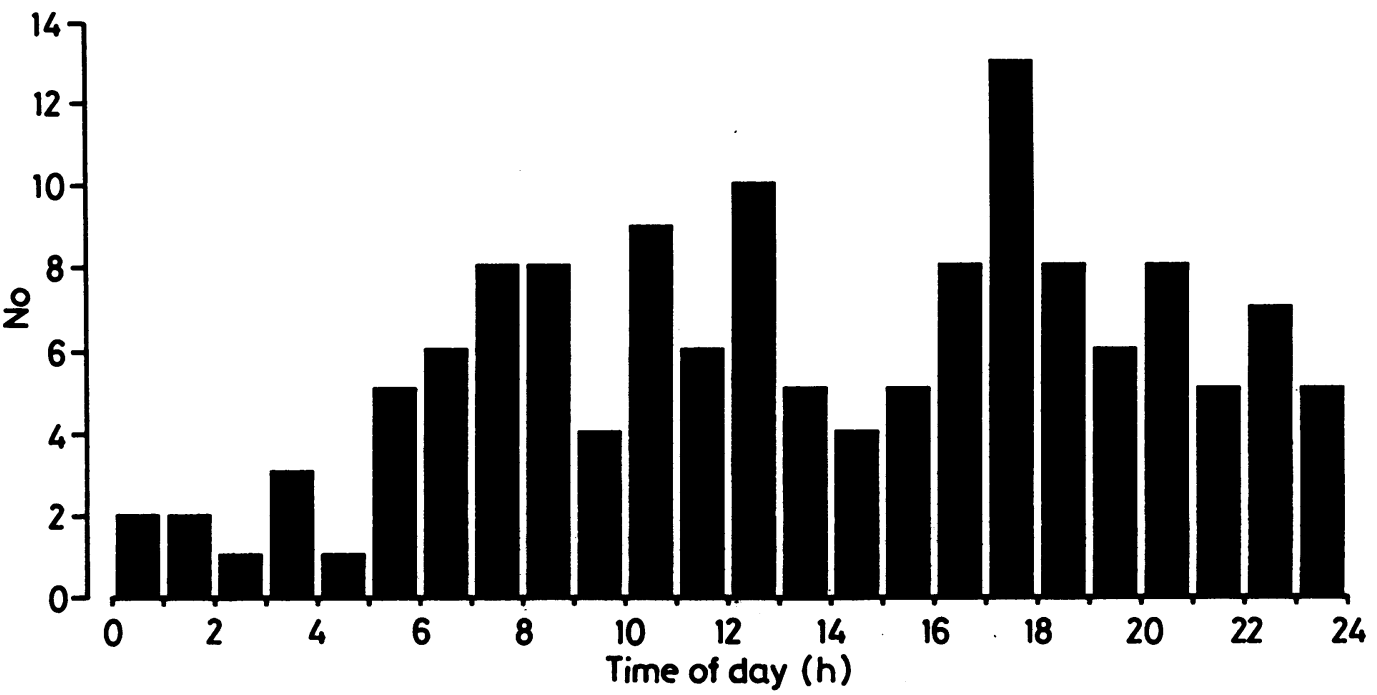

2200. This distribution of paroxysms throughout the day was non-random $\left(\chi^{2}=13 \cdot 4, \mathrm{df}=2\right.$, $\mathrm{p}<0.005)$.

1

There were $17^{\mathrm{T}}$ prolonged episodes of atrial fibrillation lasting 30 or more minutes (range 30-1100 minutes). Their temporal distribution did not differ from that which could have occurred by chance $\left(\chi^{2}=0.82, \mathrm{df}=2, \mathrm{NS}\right)$.

PROLONGED EPISODES AND DIGOXIN TREATMENT Thirteen of 17 patients with prolonged episodes of atrial fibrillation were taking digoxin, compared with 18 out of 55 patients who did not have prolonged episodes $\left(\chi^{2}=8.4\right.$ with Yates's correction, $p<0.01$ ). The relative risk of prolonged episodes of atrial fibrillation associated with digoxin treatment was $4 \cdot 3$ (95\% confidence interval 1.6-11.9).

\section{VENTRICULAR RATES DURING PAROXYSMAL} ATRIAL FIBRILLATION

The mean (SD) ventricular rate at the start of all paroxysms of atrial fibrillation was 136 (23.6) beats $/ \mathrm{min}$. The mean ventricular rate was not significantly different in patients taking or not taking digoxin (140 (25.3) v 134 $(22 \cdot 2)$ beats/min, NS). Figure 2 shows the relation of the mean ventricular rates to calculated serum digoxin concentrations.

The mean ventricular rate at the start of prolonged episodes of atrial fibrillation was 140 (33.9) beats/min, and this was similar to that at the start of short bursts. The ventricular rate at the start of prolonged episodes was not significantly different from that immediately before spontaneous termination, when it was $138(27 \cdot 3)$ beats $/ \mathrm{min}$.

Figure 2 Mean $(95 \%$ confidence intervals) ventricular rates for patients with three calculated serum digoxin concentrations.

\section{EFFECTS OF OTHER TREATMENT}

The number and time of day of paroxysms, the number of prolonged paroxysms, and the ventricular rates were not significantly different in the small number of patients taking $\beta$ adrenergic blockers or calcium channel blockers compared with patients not taking these drugs.

\section{Discussion}

Paroxysmal atrial fibrillation is a difficult disorder to investigate because of its essentially intermittent nature. In this study, where patients were selected by virtue of the chance recording of episodes of atrial fibrillation, the incidence of attacks was slightly less than one per day, of which $88 \%$ lasted less than half an hour. Any prospective study of paroxysmal atrial fibrillation is therefore severely hampered by the difficulty of documenting the occurrence of infrequent and usually brief episodes. ${ }^{7}$ Our study was not a randomised prospective trial, and the way in which patients were selected may have resulted in bias. Nevertheless, our observations add to knowledge in this difficult area.

Atrial dilatation, a shortened refractory period, reduced conduction velocity, and nonuniform repolarisation increase the likelihood of the induction of atrial fibrillation, ${ }^{8}$ which may be triggered by an extrasystole arising from an irritable, ectopic focus. ${ }^{9}$ These conditions are found in a wide variety of physiological, pathological, and experimental states. Thus, cholinergic drugs applied directly to the atrium, ${ }^{10}$ or acetylcholine released by vagal stimulation $^{1112}$ shorten the atrial refractory period and may lead to atrial fibrillation, especially if there is atrial distension with fibrosis or other pathological features. ${ }^{13}$ Sympathetic stimulation, which may coexist with vagal activity, ${ }^{14}$ may also bring about the same end result by increasing cardiac excitability and hence the occurrence of extrasystoles. Precipitation of atrial fibrillation under clinical conditions of sympathetic or parasympathetic predominance has been described. ${ }^{4}$

Digoxin enhances vagal tone, increasing the refractory period of the atrioventricular node. In established atrial fibrillation this property of

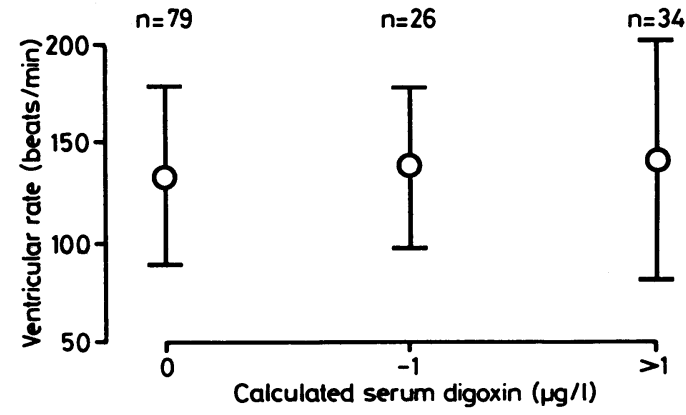


digoxin is used to increase the degree of atrioventricular block and so reduce ventricular rate. It is most effective in this when vagal tone is already high, and relatively ineffective when vagal tone is low. Thus, although ventricular rate at rest may be controlled by digoxin, during exercise, when vagal tone is withdrawn and sympathetic activity predominates, ventricular rate may be regarded as excessive. ${ }^{15}$

Digoxin also shortens the refractory period of atrial muscle, rendering the atrium more susceptible to fibrillation and increasing the rate of fibrillation should it occur. The result of its use in atrial fibrillation is therefore a compromise between increased fibrillation rate and reduced atrioventricular conduction, with the beneficial effect of the reduced conduction generally predominating.

In the patients selected for this study, paroxysms of atrial fibrillation were twice as likely to occur by day as by night, suggesting that attacks were more closely associated with sympathetic activity than with vagal activity. Attacks were as frequent in patients taking digoxin as in those who were not. Mean ventricular rates during attacks were high and no different in patients taking or not taking digoxin. This lack of benefit from digoxin may have resulted from the conditions of low vagal tone and sympathetic predominance under which most of the paroxysms may be presumed to have arisen.

While there is no evidence of reduction of ventricular rate during paroxysmal atrial fibrillation, there is evidence that the use of digoxin resulted in longer attacks, a result consistent with its action in reducing the atrial refractory period.

We thank Carole Shirreffs RGN for her help with data processing.

1 Bellet S. Clinical disorders of the heart beat. Philadelphia: Lea and Febiger, 1971:242.

2 Bigger JT. Management of arrhythmias. In: Braunwald E, ed. Heart disease: a textbook of cardiovascular medicine. Philadelphia: WB Saunders, 1980:732.

3 Coumel P, Attuel P, Lavallee JP, Flammang D, Leclercq JF, Slama R. Syndrome d'arythmie auriculaire d'origine vagale. Arch Mal Coeur 1978;71:645-56.

4 Coumel P, Leclercq JF, Attuel P. Paroxysmal atrial fibrillation. In: Kulbertus HE, Olsson SB, Schlepper M, eds. tion. In: Kulbertus HE, Olsson SB, Schlepper M,

5 Ewing DJ, Neilson JMM, Travis P. New method for assessing cardiac parasympathetic activity using 24 hour electrocardiograms. Br Heart J 1984;52:396-402.

6 Jelliffe RW, Brooker G. A nomogram for digoxin therapy. Am J Med 1974;57:63-8.

7 Hammill SC, Wood DL, Gersh BJ, Osborn MJ, Holmes DR. Propafenone for paroxysmal atrial fibrillation. $\mathrm{Am} \mathrm{J}$ Cardiol 1988;61:473-4.

8 Allessie M, Lammers W, Smeets J, Bonke F, Hollen J. Total mapping of atrial excitation during acetylcholine-induced atrial flutter and fibrillation in the isolated canine heart. In: Kulburtus HE, Olsson SB, Schlepper M, eds. Atrial fibrillation. Molndal: AB Hassle, 1984:44-59.

9 Killip T, Gault JH. Mode of onset of atrial fibrillation in man. Am Heart J 1965;70:172-9.

10 Scherf $D$. Studies on auricular tachycardia caused by aconitine administration. Proc Soc Exp Biol Med 1947;64: 233-9.

11 Lewis T, Drury AN, Bulger HA. Observations upon flutter and fibrillation. Part VII-The effects of vagal stimula and fibrillation. Part VII-

12 Allessie R, Nusynowitz M, Abildskov JA, Moe GK. Nonuniform distribution of vagal effects on the atrial refractory period. Am J Physiol 1958;194:406-10.

13 James TN. Diversity of histopathologic correlates of atrial fibrillation. In: Kulburtus HE, Olsson SB, Schlepper M, eds. Atrial fibrillation. Molndal: AB Hassle, 1984:13-30.

14 Bellet S. Clinical disorders of the heart beat. Philadelphia: Lea and Febiger, 1971:585.

15 Beasley R, Smith DA, McHaffie DJ. Exercise heart rate at different serum digoxin concentrations in patients with atrial fibrillation. $\mathrm{Br}$ Med J 1985;290:9-11. 